\title{
Life Cycle Assessment of Agricultural Wood Production-Methodological Options: a Literature Review
}

\author{
E. Alejandro Perdomo E. ${ }^{1}$ - Peter Schwarzbauer ${ }^{2}$ - Daniela Fürtner ${ }^{1}$ • Franziska Hesser $^{1,2}$ (D)
}

Received: 8 July 2020 / Accepted: 26 February 2021 / Published online: 10 March 2021

(C) The Author(s) 2021

\begin{abstract}
In Europe, poplar and other fast-growing tree species are considered valuable resources for meeting the required wood demand of the rising bioeconomy. The agricultural technique of short rotation coppice (SRC) has gained relevance to ease the pressure of the demand for wood from forests. Previous studies have implemented the life cycle assessment (LCA) methodology to evaluate such systems' potential environmental impacts. These studies present different outcomes, though a general pattern on the potential benefit of SRC is observed. The variation of relevant methodological options, such as goal and scope, system boundary, functional unit, reference system, data source, characterization models, and impact categories assessed can significantly affect the results. A consequence of this discrepancy is its effect on results' interpretation, making the absolute comparison of case studies challenging and hindering the understanding of the potential impacts of SRC LCAs in support of developing a sustainable bioeconomy. Therefore, the current research attempts to understand the methodological implementation of LCA in assessing SRC value chains. Through literature research, studies are analyzed based on the four LCA phases. One of the results of this study shows how most of the articles focus on assessing the impact category related to climate change, while other environmental issues that are particularly relevant for agricultural woody biomass systems are seldomly evaluated. By discussing the state of the art of SRC LCA, this review paper attempts to suggest improvements that will allow future LCA studies to reach a more comprehensive understanding of the overall environmental impact of SRC systems.
\end{abstract}

Keywords Bioeconomy $\cdot$ Environmental assessment $\cdot$ Short-rotation coppice $\cdot$ Dendromass $\cdot$ Sustainability

\section{Introduction}

Wood is considered one of the primary biomass materials to substitute for fossil-based alternatives, representing an essential pillar to fuel the bioeconomy. Different studies predict that establishing a sustainable bioeconomy can increase the wood demand and exceed the supply by 2030 in the European Union $[1,2]$. This will exert pressures on the forest ecosystem services such as nutrient cycles, carbon storage, water, and air purification [3]. Agricultural wood production from fastgrowing short rotation coppices (SRC) can help to meet the

Franziska Hesser

franziska.hesser@boku.ac.at

1 Wood K plus - Competence Centre for Wood Composites and Wood Chemistry, Kompetenzzentrum Holz GmbH, Altenberger Straße 69, 4040 Linz, Austria

2 Department of Economics and Social Sciences, Institute of Marketing and Innovation, University of Natural Resources and Life Sciences Vienna, Gregor-Mendel-Straße 33, 1180 Wien, Austria increasing wood demand [4] by its potential to produce large amounts of woody biomass cost-effectively in relatively short rotation cycles [5]. Nevertheless, like forest-based wood production, SRC plantations also cause environmental impacts, for example, on water and soil quality [6]. During the last decade, an increasing number of life cycle assessments (LCA) attempted to model SRC value chains' potential environmental impacts [7-9]. However, LCA results are influenced by the selected methodological options, for instance, when defining to which alternatives SRC is compared or which environmental impacts are studied [10]. Consequently, this challenges the overall understanding of SRC systems' potential environmental impacts. To improve the understanding of potential environmental impacts associated with wood production in SRC systems, it is relevant to identify the state-of-the-art of LCA studies, their findings, and shortcomings on SRC and comprehend which conclusions were drawn.

Previous researchers have addressed similar problems; for instance, Pawelzik et al. [10] developed a review of bio-based LCAs. Among the most important outcomes, the study 
remarked upon the relevance of quantifying impacts on land use and biodiversity. More recently, D'Amato et al. [11] focused on reviewing forest-based product LCAs connected to ecosystem service impacts in the context of the bioeconomy. Their study found that the most assessed categories were climate change, ozone, eutrophication, human toxicity, resource depletion, acidification, and environmental toxicity. After linking the encountered impact categories to ecosystem services, they observed that only $20 \%$ of ecosystem services were included in forest-based LCAs. Despite the similarities between forest-based and agricultural wood production, in terms of the wood being produced, the management of SRC systems is more analogous to annual crops than to forest systems [12]. For instance, SRC land use management can include land preparation, irrigation, fertilizer and pesticide application, soil erosion, carbon sequestration potential, and land remediation. These differences highlight the importance of performing LCA studies on SRC projects.

The LCA is a standardized methodology for the assessment of potential environmental impacts induced by human activity [13]. Different methodological options arise from the flexibility of LCA itself, from methodological developments, evolving needs in assessments due to the policy environment or environmental challenges. There is no specific guideline for implementing an LCA on SRC value chains. Other requirements, standards, or documents, such as ISO standards, Product Category Rules (PCRs) of the International Environmental Product Declarations (EPD) System, EU sustainability criteria, or product environmental footprints (PEFs), do not specifically mention SRC. However, suggestions on methodological options when carrying out an LCA of SRC and other bio-based materials have been presented [10]. For instance, Djomo et al. [14] mentioned the importance of including a reference land use within the system boundaries defined since the conversion of agricultural and forest land to SRC plantations affects soil organic carbon (SOC). Moreover, Hansen et al. [15] mentioned how the uncertainties about the SOC accumulation have an essential impact on the overall carbon mitigation potential of SRC systems. A study that reviews recent SRC LCAs and summarizes relevant interdependencies between methodological options and study outcomes has not yet been carried out.

This study aims to close this gap by identifying and discussing how LCA is used in SRC value chains. A literature review of previous SRC LCAs will help to understand which effects different methodological options have on the conclusions of the environmental impacts. Moreover, the study helps to comprehend the overall interpretation of SRC LCA studies that can contribute to the SRC community and those interested in communicating such results in support of a sustainable bioeconomy. To reach this aim, a descriptive investigation applying a literature review was conducted. The study objectives are the following:
1. Examine the state of the art of LCA studies on SRC to identify which methodological options are implemented.

2. Identify implications of methodological options on the conclusions of the potential environmental impacts of SRC.

3. Derive gaps in the LCA study of SRC and propose a research outlook for improving the understanding of potential environmental impacts associated with wood production in SRC systems.

\section{Background}

Following the International Standard Organization (ISO) 14040 [13], LCA as a method has been developed to assess the potential environmental impacts of systems and products through their life cycle. Studies focusing on LCA vary in their applications, including product development and improvement, strategic planning, and informing policymakers. As depicted in Fig. 1, the methodology consists of an iterative process involving the interaction between four main phases. The following subchapters introduce these phases.

\section{Goal and Scope Definition}

As the first phase, the goal and scope consist of providing an overall framing of the study's aim. According to the ISO standards [13], this should integrate and clearly describe the study's intended application, state why the research is being carried out, and identify the intended audience, the product system, the functional unit (FU), and system boundary (SB).

The product system definition describes all the system functions and involved processes. This description is the foundation for the FU definition, which provides a reference to all the product system inputs and outputs. Usually, the FU attempts to represent a product's function rather than the physical properties, allowing comparisons between different systems.

The ISO standards mention that an LCA study intends to perform an assessment "throughout a product's life cycle, from raw material acquisition (cradle) through production, use, end-of-life treatment, recycling, and final disposal (grave)" $[15$, p. 5]. The SB definition represents a helpful criterion to decide whether a life cycle step or process is included in the analysis. Common terminology for describing an SB that consists of a product's whole life cycle is "cradle to grave" (CtGr). Other variants of LCA's SB are those that consider a partial representation of the life cycle, for instance, "cradle to gate" ( $\mathrm{CtGa})$, "cradle to farm gate" ( $\mathrm{CtFG})$, and "gate to gate" (GtG). The first two refer to assessing a partial product life cycle from resource extraction (cradle) to the 


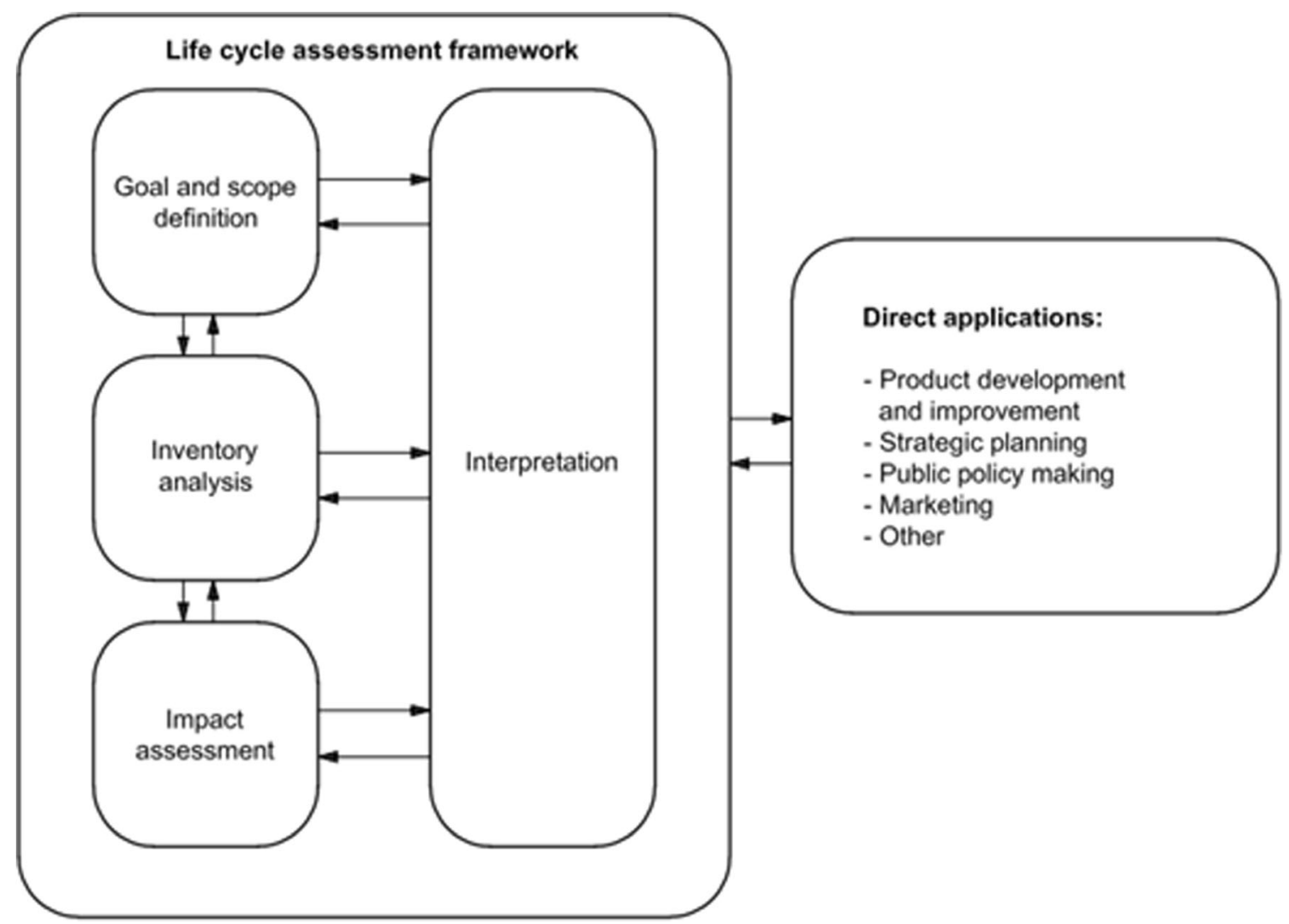

Fig. 1 Life cycle assessment framework [13]

factory gate or farm gate. The GtG approach focuses on only one value-added process [16].

LCA studies can be further classified depending on the system modeling approach. Attributional LCA (ALCA) refers to studies that account for impacts associated with the physical changes during the life cycle, thus a cause-oriented perspective. Consequential LCA (CLCA) examines the effects of the environmental impacts produced by the life cycle, hence an effect-oriented view. In other words, ALCA estimates only the environmental burden of a product, whereas CLCA expands the focuses to study the effects that the product burden has on an external environment (e.g., a market change generated by producing the product).

\section{Inventory Analysis}

Through the life cycle inventory (LCI), the LCA practitioner collects all the product system flow data. The LCI is one of the most time-consuming LCA phases since all inputs and outputs such as resources, emissions, and products are gathered throughout the product's life cycle. A practical strategy is to divide the system in terms of "background" and "foreground." The background consists of processes that cannot be influenced directly by the decision-maker (e.g., production of electricity supply). The foreground consists of those that can be modified (e.g., processes within the defined product system).
The data can be collected from different data sources, classified as primary or secondary sources. Generally, a first-hand source, usually called primary data (e.g., from experiments) source, is used to collect information on the foreground system, whereas secondary sources (e.g., databases) are used for the background system.

\section{Impact Assessment}

After the data is collected, the purpose of the life cycle impact assessment (LCIA) is to relate the elementary flows to the environmental impact scores. This phase provides a clearer understanding of the system's impacts, presenting answers to the study's goal and the decision-making process [17]. The LCIA consists of five steps, which are (1) selection of impact categories, category indicator, and characterization models, (2) classification and assignment of LCI data to impact categories, (3) calculation of category indicator results, (4) normalization and weighting of results, and (5) the grouping of impact scores [18].

The first step consists of selecting which impact categories, indicators, and models are relevant to the study's goal and scope [13]. Here the practitioner decides at which point along the impact pathway the environmental impact will be measured. To help understand the pathway stages, method developers have proposed to differentiate between midpoint and 
endpoint indicators. An example of a midpoint is climate change, which can be measured based on the Global Warming Potential (GWP) indicator and calculated by different methods, such as the Intergovernmental Panel for Climate Change (IPCC) baseline model [19]. An instance of an endpoint indicator is damage to human health; the Disability Adjusted Life Years (DALY) serves as the indicator for this, calculated with the help of the IMPACT2002+ method [20]. The impact modeling selection varies depending on several factors, such as data availability, the LCA practitioners' expertise, data quality, and the product system's own characteristics. Nevertheless, the ISO standards present a list of recommended impact categories that should be measured. Additionally, several default lists of impact categories have been developed to support and facilitate the development of an LCA study [21].

The second step consists of assigning the LCI results, such as an elementary flow (e.g., $\mathrm{CO}_{2}$ ) to a selected impact category (e.g., climate change) from the previous step. Similar to the impact category lists, default lists of elementary flows exist, for instance, the Ecoinvent database, which provides datasets of previously analyzed products.

The following step calculates the category indicator by multiplying the assigned elementary flow to a characterization factor. Different impact methods are used to calculate the categorization factors $(\mathrm{CF})$, which represent the determined contribution of an elementary flow (e.g., $\mathrm{CO}_{2}$ ) to the impact category (e.g., GWP). The CF is expressed as per unit emission or resource consumption (e.g., $\mathrm{kg} \mathrm{CO}_{2}$ eq per unit) [22].

Considered as optional within the ISO standards [13], the forth step consists of first normalizing the previously calculated values by comparing the results with a global, regional, national, or industrial reference system. This calculation brings all the results into the same set of information, allowing an impression of the indicator's relative magnitude. After the normalization of the impacts, the weighting step can be carried out. The weighting or aggregation is done by applying weights to each normalized category indicator. The weighting factors are subjective according to the practitioner's or involved stakeholders' choices and need to match the goal and scope definition [23].

The last step consists of grouping the characterization results into different sets based on global or regional impacts, or based on ranking defined by a selected criterion. This step is done to ease the interpretation of the results, and it is also optional within the ISO standards [13].

\section{Interpretation}

The interpretation phase is the fourth and final step in the LCA study. It combines the results of the LCI and the LCIA to determine the potential environmental impacts of the value chains. The results and conclusions presented in this phase should be in coherence with the previously defined goal and scope. Moreover, the limitations and uncertainties of the study are clarified.

\section{Method}

This study carried out a literature review of peerreviewed articles and books using the scientific databases Science Direct and Scopus to encounter the objectives stated. The focus was to identify literature on SRC value chains, LCA, environmental sustainability, and agricultural wood production. Additionally, to extend the search and identify any possible relevant research, the review included synonyms of the previously mentioned topics. Consequently, after an iterative process [24], the search considered the following refined search: "Short rotation coppice" OR "SRC" OR "SRP") AND ("life cycle assessment" OR "LCA" OR "Environmental sustainability") AND ("Dendromass" OR "agricultural wood production" OR "Woody biomass" OR "Woody crops") AND ("value chain" OR "supply chain").

From this search, 186 results were obtained. As the LCA of SRC and the bioeconomy is a recent phenomenon [11], it was decided to limit the investigation to the time frame from 2000 to 2020. An initial screening was based on titles and abstracts. Moreover, a further selection criterion was to consider literature that (i) was written in English (conference proceedings, literature reviews, and abstracts alone were excluded), (ii) applied LCA as the environmental assessment method (studies that referred only to energy, economics, and business sustainability were excluded), and (iii) stated that the woody biomass is produced from agricultural lands. After the full-text screening, additional documents that did not meet the inclusion criteria were excluded, leading to a final sample of 40 articles $(n=40)$.

The collected articles were afterward analyzed using descriptive content analysis. Firstly, the methodological options implemented were extracted considering an inductive procedure based on the four structural and procedural components of LCA phases (goal and scope, life cycle inventory, life cycle impact assessment, and life cycle interpretation). Subsequently, the obtained data was analyzed quantitatively using statistical analysis. This step helped to determine patterns of implemented methodological options, interdependencies, and outcomes (e.g., potential environmental hotspots). Previous literature on biomass production (e.g., [25]) and LCAs of bio-based systems and agricultural systems (e.g., $[11,26]$ ) served to help inform the analysis of gaps and research outlook. 


\section{Results}

The literature review provided insights into the different methodological options taken in 40 LCAs of SRC value chains, covering studies from the years 2003 to 2019. As presented in Table 1, some of the methodological options identified concerned the framing of the study's goal and scope, the system boundary definition, the function until selected, and the impact categories assessed, among others. The geographical scope of the studies includes Europe and North America.

\section{Goal and Scope Definition in LCAs of Agricultural Wood Production}

The results present that 37 out of $40(92.5 \%)$ articles referred to following the ISO guidelines [13]. Out of these 37 articles, approximately $64 \%$ clearly defined the goal and scope of the study. Another observation is that only five out of 40 (12.5\%) studies indicated their intended audience and application, even though the studies stated to follow the ISO standards. Furthermore, it was found that, besides the goal of environmental assessment, some studies also focused on energy performance $(n=12)$, system comparison $(n=7)$, and system optimization $(n=2)$. As for the LCA approach taken, seven studies mentioned using an ALCA, one article specifically framed the study as CLCA, and the majority ( 32 articles) did not explicitly mention their approach.

The woody biomass studied varied in terms of species such as poplar, willow, and eucalyptus. For those studies where the objective was to compare different biomasses (e.g., [34]), the analysis considered other feedstocks such as alfalfa, miscanthus and straw pine. Additionally, few studies specifically mentioned the genotype or species of biomass considered. Most studies referred to the general biomass species, for instance, willow (Salix spp.) [32] or poplar (Populus spp.) [27].

Regarding the system boundaries definition, it was found that about half of the studies $(n=30)$ considered a cradle to gate $(\mathrm{CtGa})$ approach. These studies were dedicated mostly to woody biomass for bioenergy. Another part of the reviewed articles $(n=5)$ considered a cradle to farm gate (CtFG) approach, in which approximately $60 \%$ of the studies focused on assessing biomass and the remainder on bioenergy. Four articles considered a cradle to grave ( $\mathrm{CtGr}$ ) approach, and one research presented a gate to gate $(\mathrm{GtG})$ assessment. The processes accounted for within the defined system boundaries varied in some studies. For instance, the definition of CtFG by Clarke et al. [9] did not account for the end of the plantation period and the emissions related to it. Contrarily, Lovarelli et al. [30] included the end phase by considering soil restoration after the end of the plantation.

\section{Functional Unit}

As the FU selection is closely related to the study goal and the evaluated production system, the results present a comparison between the study's focus and system boundaries. The outcome showed that most studies that focused on woody biomass for bioenergy considered the FU to be in terms of energy units; nevertheless, other studies used the area unit of, for instance, 1 ha. Those studies that focused only on the biomass production with a system boundary CtFG considered mostly the FU of $1 \mathrm{t}$. Consequently, to understand the methodological patterns of the studies, three groups of FUs are encountered: cultivated area (ha), harvested volume (ton), and energy (e.g., $\mathrm{MJ}$ ). The following pattern is observed between the FU groups, system boundaries, and study focus: (i) most studies focusing on biomass for bioenergy (e.g., thermal, and electric energy) used an energy unit as FU, (ii) studies assessing only the biomass production referred to volume units.

Among the reviewed publications, the definition of the FU varied. The results present a total of 10 different FUs as shown in Table 1. The most frequent FU was the energy unit "Joules," considered in 37.5\% ( $n=15)$ of the studies, followed by the mass unit "tonnes" evaluated in $25 \%(n=10)$, and the area unit "hectares" in $22.5 \%(n=9)$. A variation to this last FU was $1 \mathrm{ha} /$ year (in 5\% of the studies). Another energy unit was 1 watt.hour $(\mathrm{Wh})$, considered in $15.0 \%(n=6)$ of the reviewed articles. The rest of the articles referred to using a distance unit $(\mathrm{km})$ and different volume units (e.g., $1 \mathrm{~m}^{3}$ biomass and $1 \mathrm{~m}^{3}$ particleboard).

Within the case studies that adopted the FU of tonnes, the predominant trend was t d.m. $(n=10)$, whereas the remaining $(n=1)$ studies applied t f.m. Additionally, $45 \%(n=18)$ articles reported the wood moisture content, which is relevant for understanding biomass-related calculations. Interestingly, only one article within the articles dealing with ton FU defined the moisture content assumed.

\section{Life Cycle Inventory (LCl)}

It was encountered that only a small percentage $(15.0 \%)$ of the reviewed papers clearly described their selected foreground and background systems. For instance, Parajuli et al. [34] considered the background system as those processes involved in production of the material inputs (e.g., chemicals, machinery, fuel, fertilizers, seedings). The foreground system considered the downstream processes, meaning all the agricultural operations and the production phase. An example can be taken from Caputo et al. [41], where the constructed LCA model includes the impacts from the necessary inputs (e.g., extraction of oil) but does not refer to this as the foreground or background system.

The selected studies dealt with a total of 9 data sources as presented in Table 2. The most frequent data source was 


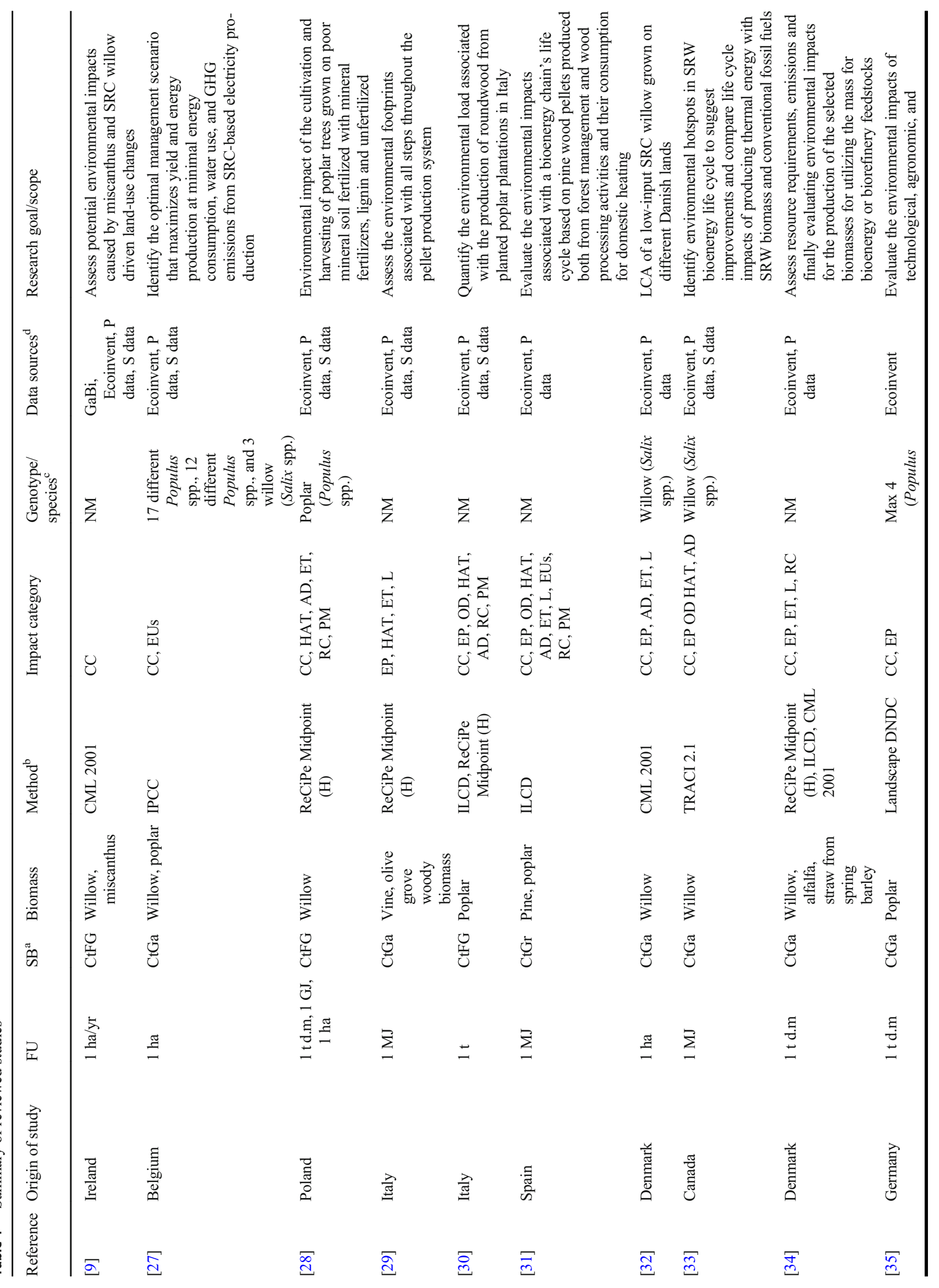




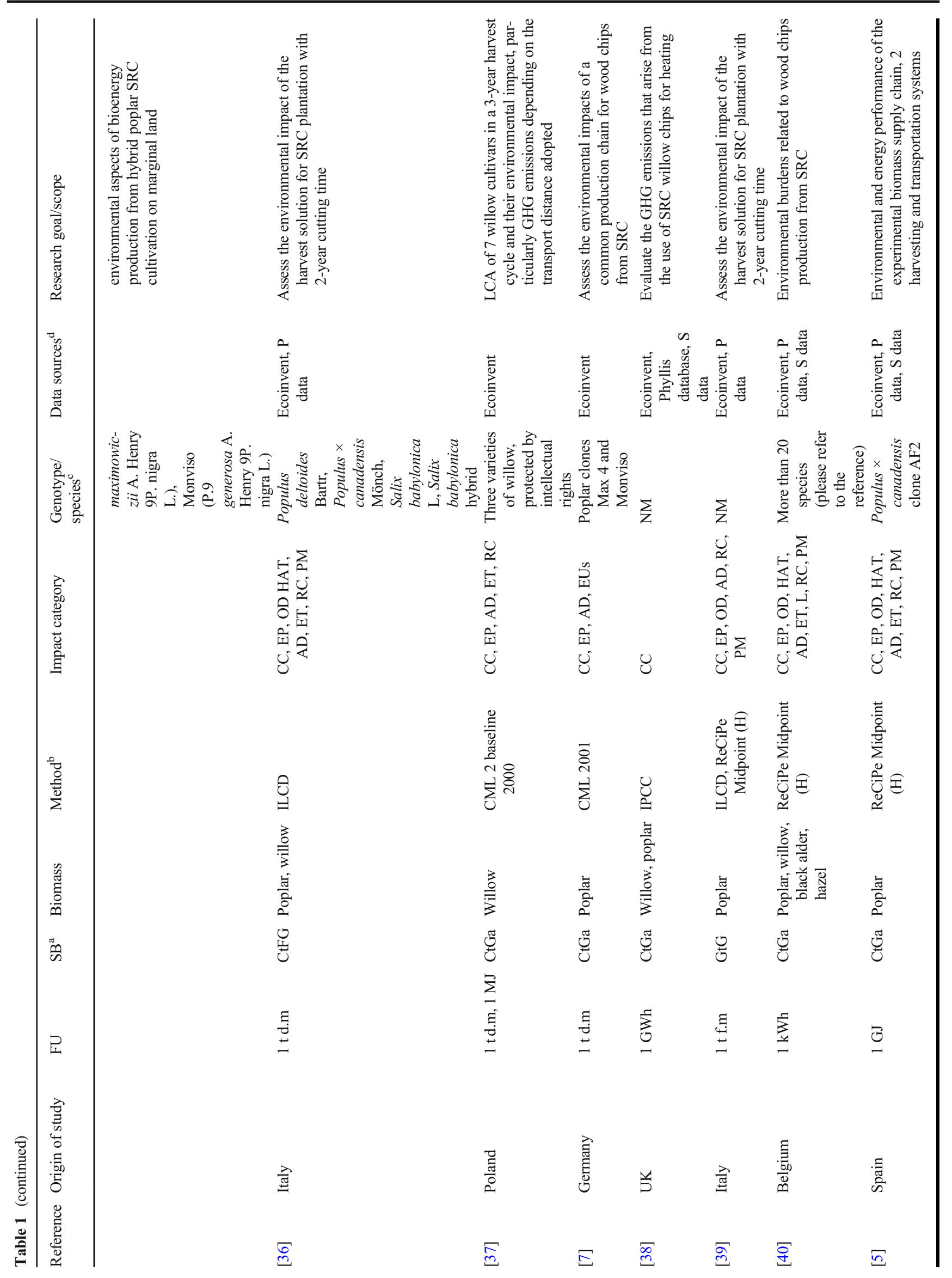




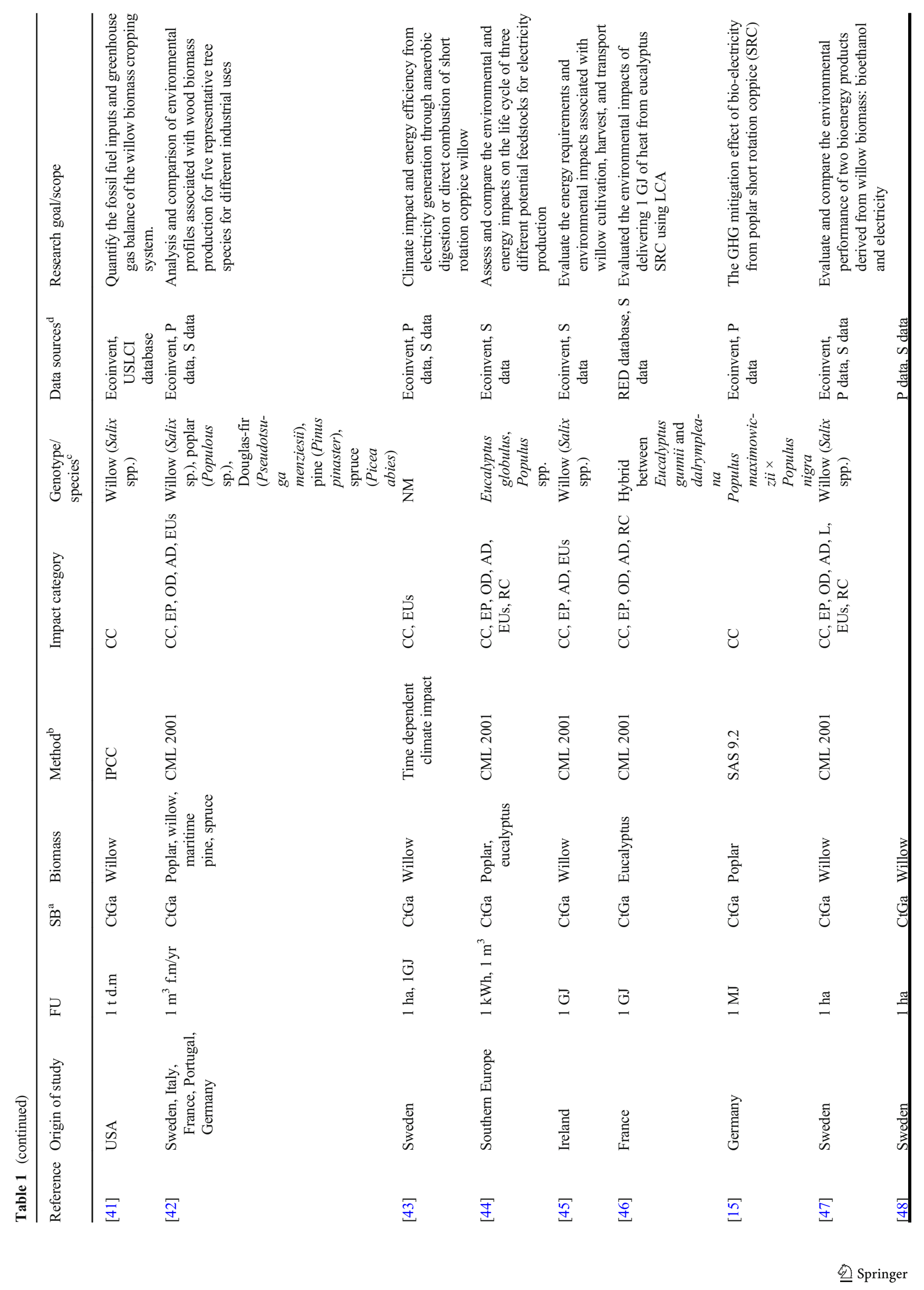




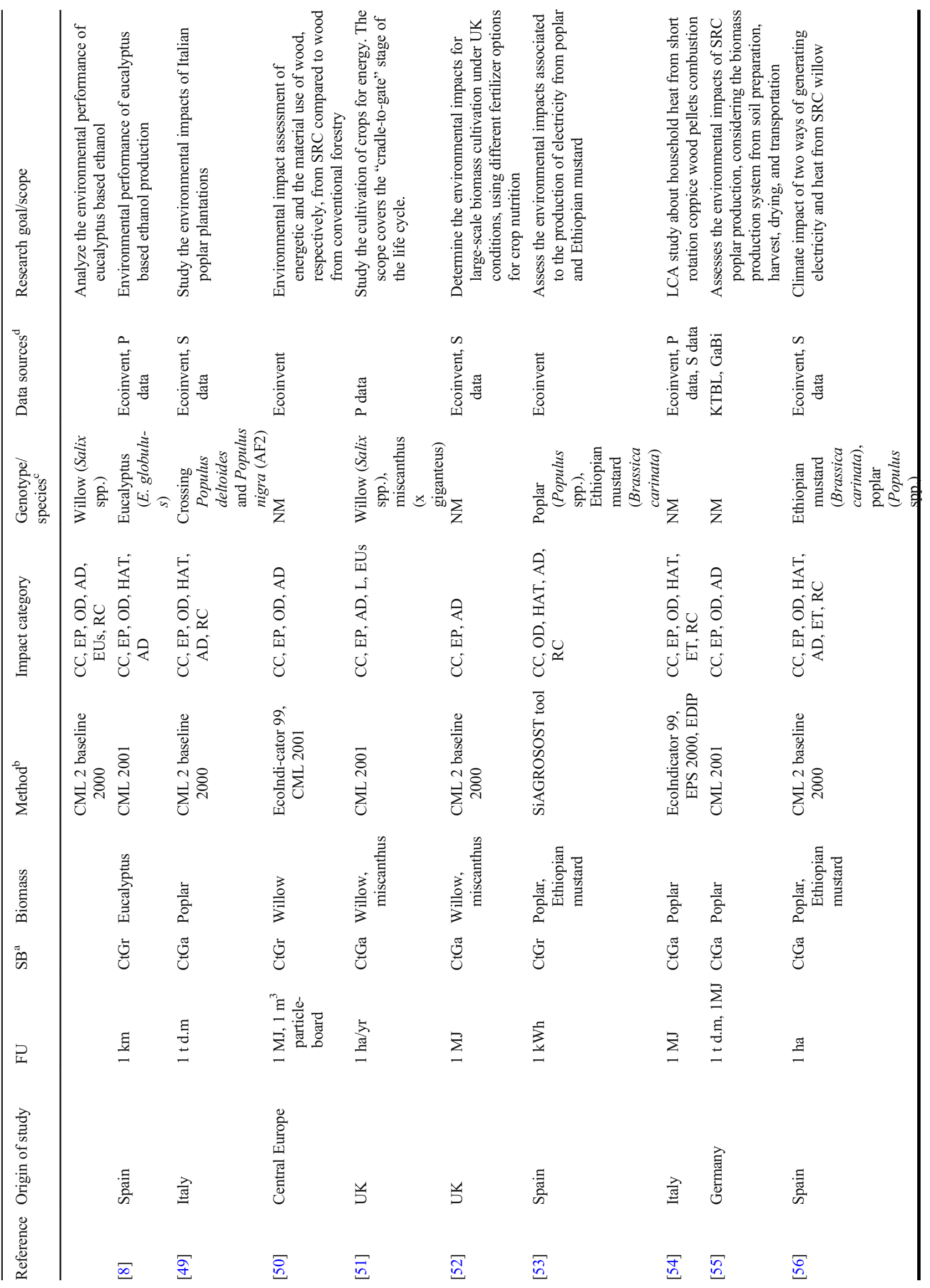




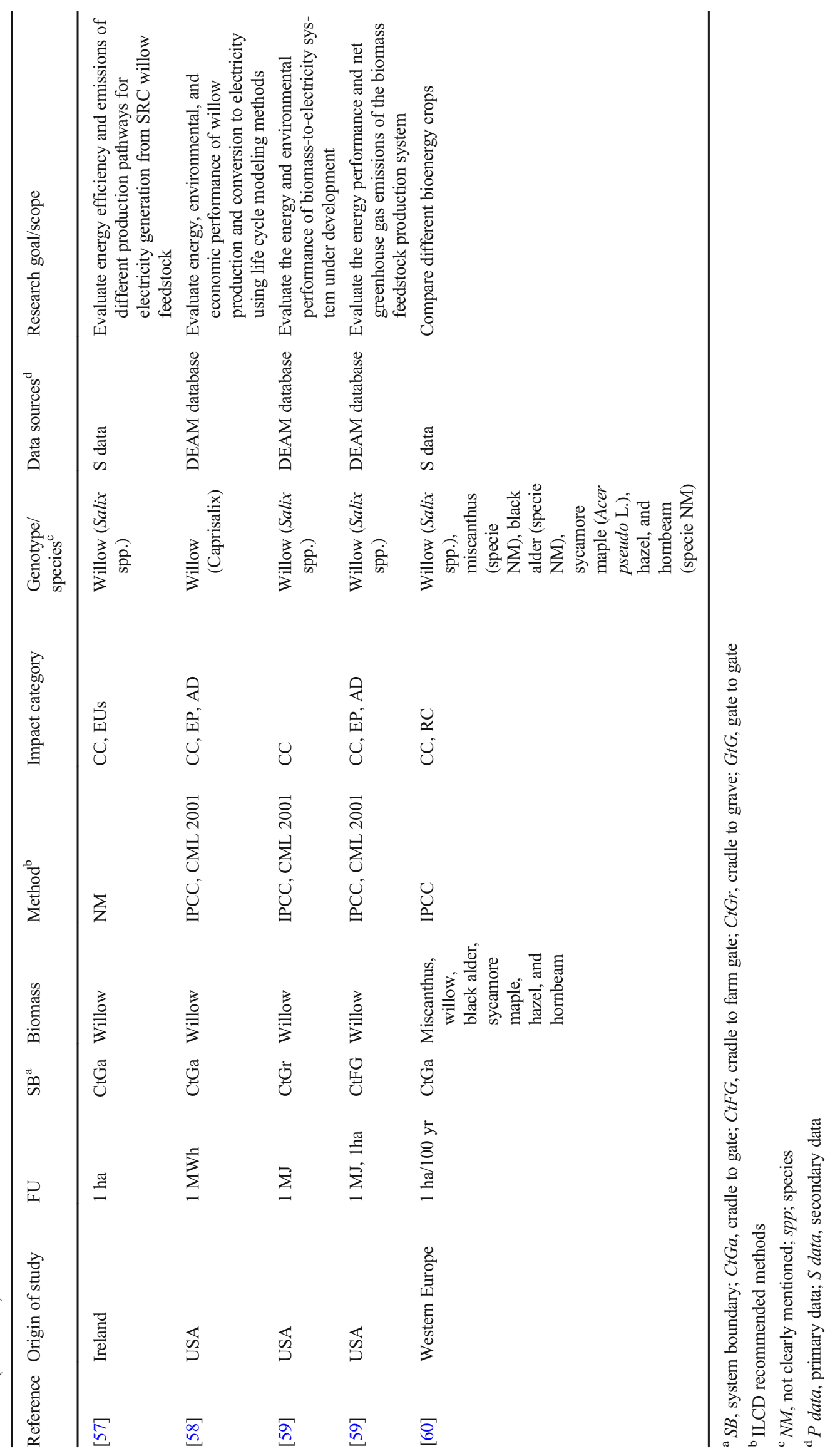


Table 2 Data resources within the reviewed studies

\begin{tabular}{lll}
\hline Source & Frequency & $\%$ \\
\hline Ecoinvent database & 31 & 77.5 \\
Secondary data (literature) & 22 & 55.0 \\
Primary data & 21 & 52.5 \\
DEAM database & 3 & 7.5 \\
GaBi database & 2 & 5.0 \\
USLCI database & 1 & 2.5 \\
RED database & 1 & 2.5 \\
KTBL & 1 & 2.5 \\
Phyllis database & 1 & 2.5 \\
\hline
\end{tabular}

secondary data, which was derived from a mixture of database sources and previous literature. The Ecoinvent database was the main resource, as $75 \%$ of the studies used this data source. Previous literature data was presented in 55\%. Other data sources were as follows: DEAM database $(7.5 \%), \mathrm{GaBi}$ database (5.0\%), USLCI (U.S. Life Cycle Inventory Database) database (2.5\%), RED database (2.5\%), KTBL (2.5\%), and Phyllis database $(2.5 \%)$. It is important to note that the data within the mentioned databases also rely on secondary data, such as published articles and available statistics [61]. Regarding primary data from own field measurements or laboratory, it can be seen that $52.5 \%$ of the studies used this source. Furthermore, studies that used primary data also relied on secondary data sources. For instance, Rugani et al. [40] used the Ecoinvent database for retrieving background data, whereas primary data were collected from project partners.

When comparing the studies' geographical location with the data sources, a correlation between the database and location prevails. Studies carried out in the USA considered USLCI and DEAM databases, whereas all the other mentioned databases, for instance, the Ecoinvent database, were generally used for those studies in Europe.

\section{Life Cycle Impact Assessment (LCIA)}

In order to facilitate the interpretation of the results, the impact categories were grouped depending on the following macrocategories: climate change (CC), eutrophication (EP), acidification (AD), ozone depletion (OD), resources consumption (RC), human toxicity (HAT), energy use (EUs), environmental toxicity (ET), land (L), and particulate matter (PM). Within each of these categories, the respective individual midpoint and endpoint categories were localized. A summary of the encountered impact categories is presented in Fig. 2. Climate change related categories, as GWP and GHG, were the most frequent impact categories considered, as they were included in almost all the review articles, covering $97.5 \%$. Following were the categories of eutrophication and acidification, with
$72.5 \%$ and $67.5 \%$, respectively. Ozone depletion and resource consumption were included in less than half of the papers, precisely $47.5 \%$ and $45 \%$, respectively. The rest of the indicators were considered in less than $35 \%$ of the studies. The indicators that were evaluated the least were those related to L and PM.

A comparison of environmental impacts was discussed by Bacenetti et al. [39]. The authors present that the CC impact of SRC poplar plantations ranges between 26.44 to $49 \mathrm{~kg}$ $\mathrm{CO}_{2}$ eq $\mathrm{t}^{-1}$. This range is extracted from previous case studies [9, 46, 53, 62, 63]. Though this comparison is stated, it is also underlined that a direct comparison in absolute terms is restricted to the LCA methodological options of the different case studies.

Concerning the environmental impact assessment methods, $87.5 \%(n=35)$ of the studies directly defined the method used. Within these studies, 11 different methods were considered. The method by the University of Leiden, named CML (Centrum Milieukunde Leiden), was the most frequently applied $(50 \%, n=20$ out of 40$)$. The ReCiPe Midpoint $(H)^{1}$ and the IPCC method were the second most used methods (17.5\%). The ILCD (International Reference Life Cycle Data System) [17] was adopted in $12.5 \%$ of the relevant studies. Several studies used a combination of methods in order to calculate the different impact categories. For instance, Parajuli et al. [34] used the EPD recommended methods [65], the ReCiPe Midpoint, and the ILCD recommended methods to calculate separate categories. The USEtox midpoint model, as suggested by the ILCD, served for environmental toxicity, the ReCiPe Midpoint for land-related impacts, and the CML 2001 baseline for CC and EP (EPD suggested methods). Another example is Saez de Bikuña et al. [32], who used a set of four impact categories chosen from the CML 2001 method. The impact categories analyzed were chosen at a midpoint level, such as CC, EP, AP, and HAT. Land use impacts were considered not as a midpoint indicator but as part of GWP emissions. As for all the other impact assessment methods, these were implemented in less than $5 \%$ of the studies.

Moreover, it was found that the selection criteria of impact categories and their assessment method were rarely stated in the reviewed articles. In some instances [32], the criteria were referred to in previous studies of similar systems. Nevertheless, a clear description of why the selected categories were included was mostly absent.

Another investigated aspect concerned the inclusion of normalization and weighting of the impact category results. For the reviewed studies, approximately $20 \%(n=8)$ of the studies considered the normalization step, and even fewer considered

\footnotetext{
1 "The acronym also represents the initials of the institutes that were the main contributors to this project and the major collaborators in its design: RIVM and Radboud University, CML, and PRé" [64, p. 5].
} 


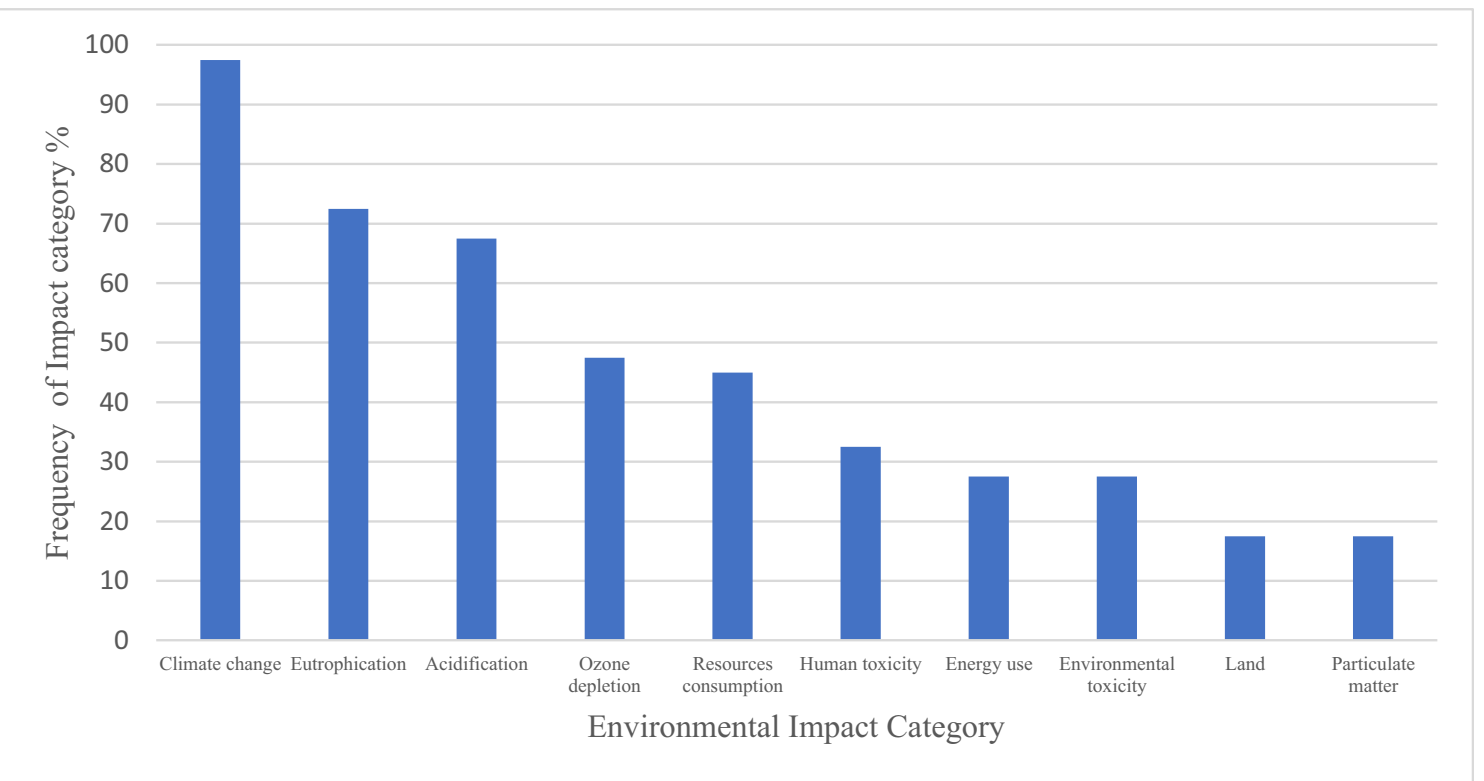

Fig. 2 Frequency of environmental impact categories analyzed in the reviewed studies $N=40$

the weighting step $(7.5 \%, n=3)$. For example, Krzyżaniak et al. [28] implemented normalization using the ReCiPe's European hierarchical version for all the evaluated impact categories. Another example is Kunstmann [50] who considered both normalization and weighting. The normalization is done comparing the results to the total inventory of mass and energy used in Western-Central Europe. For the weighting, relevant stakeholders helped to deduce the factors; however, a discussion on how they were selected is not presented. Another example of weighting is Fantozzi and Buratti [54], who used elements based on the EDIP method that applies the environmental targets proposed by the Danish Government or the International Protocols. The implementation of both normalization and weighting is dependent on the goal and scope. Its subject matter requires that those studies performing this step clearly state their selection criteria.

\section{Life Cycle Interpretation}

The studies' results were mostly presented based on the life cycle steps of the agricultural wood production system. However, the heterogeneity of the case studies and the functional unit selection, system boundary, and impact categories evaluated make the comparison of the results of the LCA models challenging. Nevertheless, to have an overview of the relevant outcomes, a quantification of the most mentioned environmental hotspots in terms of the life cycle steps is presented in Fig. 3. The hotspots are defined as the process that has the highest environmental impacts. As a quantitative comparison between the studies was not feasible, hotspots were extracted qualitatively from the reviewed studies; meaning that a hotspot was noted when a review study was found to mention a process with a high environmental impact.
Fertilizer and harvesting activities were considered to have the highest environmental impact in 50\% of the studies. The fertilizer activities concern production and field application. For instance, Krzyżaniak et al. [28] reported that, for the impact category GWP, a reduction of GHG emissions is possible by reducing or substituting the use of mineral fertilizer. Moreover, attention is also drawn to the impact category EP, which is affected by mineral fertilizer use. In comparing different agricultural management systems, Schweier et al. [7] presented how fertilization and irrigation could increase the GWP of the system by approximately $220 \%$, particularly by an increase of nitrous dioxide $\left(\mathrm{N}_{2} \mathrm{O}\right)$ emissions, which strongly influences the overall impact. Additionally, it is also mentioned how fertilizer use affected the EP category, adding nitrates and phosphates. From a different perspective, the study of Goglio and Owende [57] analyzes different fertilizer types and application techniques, for example, the use of sewage sludge instead of mineral fertilizer. Results show that this change of fertilizer type only increases the $\mathrm{CO}_{2}$ emissions by $1.7 \%$. Nonetheless, they present fertilizer activities as one of the hotspots of the agricultural wood production system.

The harvesting operation, also the major hotspot in $50 \%$ of the studies, usually occurs during each rotation cycle of SRC, for instance, in cycles of $1,2,5,10,15$, or 20 years. This energy-intensive operation often includes the forwarding process. Bacenetti et al. [36] presented harvesting as having one of the highest contributions to the field operations for almost all the twelve impact categories assessed, like those related to $\mathrm{CC}$, $\mathrm{OD}, \mathrm{AD}$, and $\mathrm{EP}$, the highest being for marine eutrophication (ME) and terrestrial eutrophication (TE). Another instance is the study by González-García et al. [47], which presents that the harvesting operations are the main contributors to GWP due to the diesel combustion. Similar results were given for other impact categories related to $\mathrm{RC}, \mathrm{AD}, \mathrm{EP}$, and OD. 


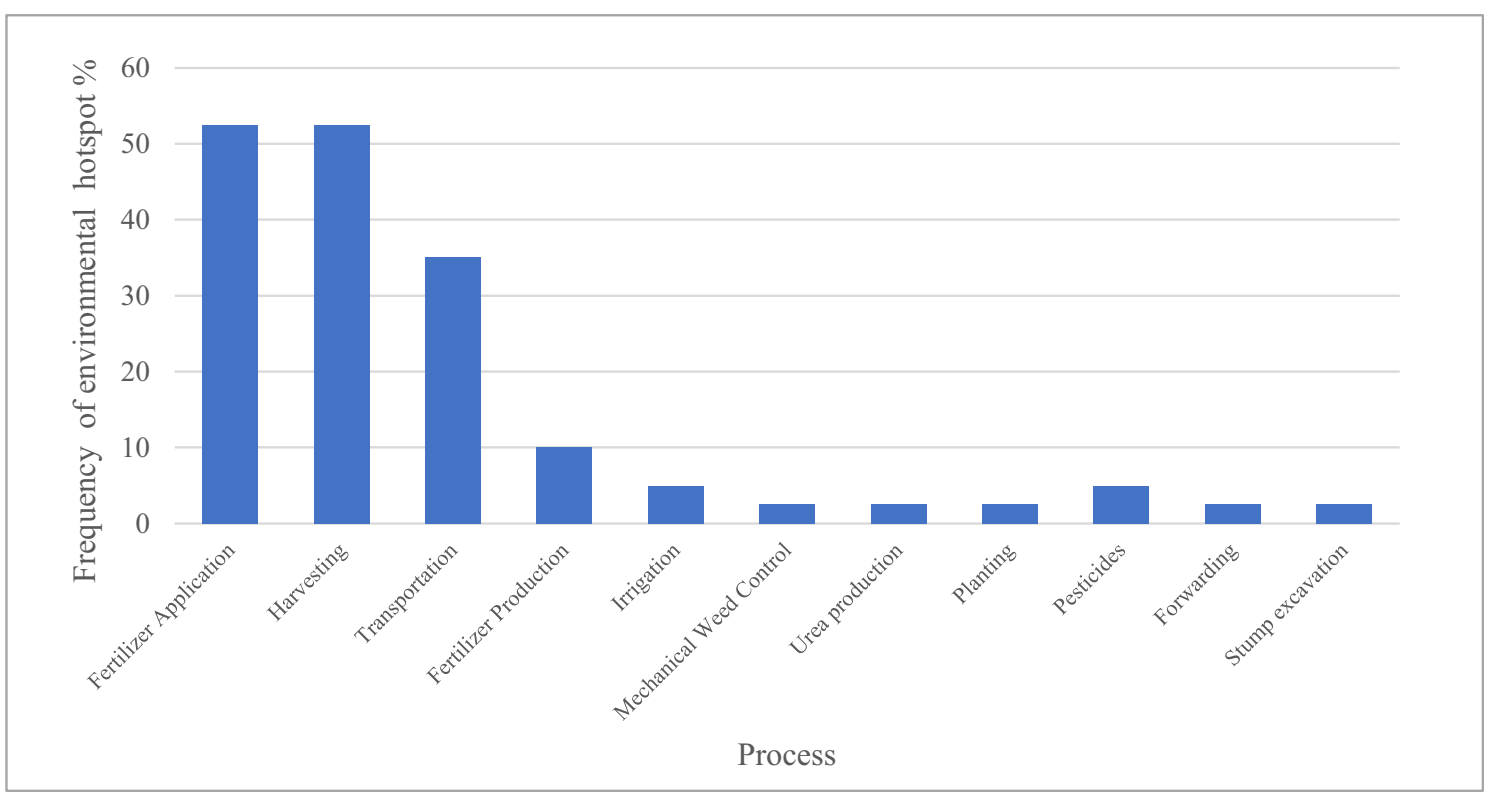

Fig. 3 Frequency of environmental hotspots identified in reviewed studies $N=40$

The third most mentioned operation is transportation, identified in $35 \%$ of the studies. This operation varies between the project specifications, including the transportation of cuttings, material inputs (e.g., fertilizer and sludge), transportation to storage, and biomass transportation from the farm gate to industry. For instance, as part of the results from Whittaker et al. [38], it is estimated that all the transportation-related events represent the second biggest GHG emitter. Similar results were presented by Gilbert et al. [52], who also mentioned the contribution of transportation to EP. Transportation emissions could be impacted by transportation distance, truck's carrying capacity, the biomass's weight, and the biomass yield $[11,50]$.

Within the studies that considered irrigation, this process also surged as an environmental hotspot. For instance, Bacenetti et al. [36] concluded that irrigation was the process that had the highest impacts on CC, HAT, EP, and RC. Schweier et al. [7] also presented a similar conclusion on the impact of irrigation, they draw attention to the required energy demand. Irrigation and fertilization are usually implemented to increment the biomass yield; their usefulness is proportional to factors such as water availability, soil type, and soil fertility. Accordingly, the use of irrigation and fertilization varies from case to case, and as mentioned by the previously selected studies, it should be considered if its effect on biomass yield compensates for the negative environmental impacts. However, Djomo et al. [27] discussed the questionable positive correlation between irrigation and biomass yield for their particular case study.

Other environmental hotspots mentioned were those of mechanical weed control, planting, pesticides, and stump excavation. However, they were only reported in less than $3 \%$ of the studies. All the other operations were not mentioned in any of the considered studies.

\section{Sensitivity Analysis}

Furthermore, as part of the life cycle interpretation phase, an assessment of the results, a sensitivity and uncertainty analysis are recommended by the ISO 14044 [13]. Within the evaluated studies, almost half $(47.5 \%)$ performed a sensitivity analysis, and only $22.5 \%$ carried out an uncertainty analysis. Depending on the study's goal, the sensitivity analysis targets issues such as data uncertainty, scenario analysis, methodological options, LCIA method, and allocation method. Lovarelli et al. [30] focused on two aspects, the methodological options concerning allocation and the key scenario parameters like the biomass yield. Rajabi Hamedani et al. [29] focused on the elements of data uncertainty and the impact assessment method. For the first part, the analysis consisted of evaluating the input data within a range of $\pm 10 \%$. The other factor involved the results' outcomes when using $\mathrm{ReCiPe}$ midpoint $(\mathrm{H})$ and CML methods.

\section{Discussion}

The results allowed for addressing the knowledge gap of reviewing recent SRC LCAs and summarizing relevant interdependencies between methodological options and study outcomes. Through this analysis, it was possible to derive gaps in the LCA study of SRC and propose a research outlook for improving the understanding of potential environmental impacts associated with wood production in SRC systems. 


\section{SRC LCA Methodological Implementation}

The identified diverse methodological implementation of SRC LCAs is plausible due to the various study foci. Starting with the system definition, most selected FUs corresponded to the phases along the studied value chain. Nevertheless, some studies evaluating similar value chains and system boundaries did not always present the same FU. Such discrepancy hints that an evaluated indicator, such as energy use, is measured using a different reference, thus reflecting the variety of study foci presented in the review papers. For instance, a focus on system comparison [56] rather than system optimization [27], which justifies selecting a different FU.

As for the system boundary, most of the studies dealt with a partial LCA based on a CtGa or CtFG boundary. The boundary definition matched the focus taken by the studies, which was mostly towards system optimization and system comparison rather than assessing the overall environmental impact of SRC systems. A similar result was given in the study by D'Amato et al. [11], where they found that the focus was mostly directed at the analysis of upstream processes. Although these boundaries show a valid representation of the system, attention was drawn to the fact that most of the studies considered some sort of EoL phase within their analysis. Moreover, it was noticed that the plantation EoL was considered in most of the reviewed papers; however, this stage was treated differently among the various studies. For instance, Lovarelli et al. [30] conducted a CtFG LCA where soil restoration was equivalent to the EoL phase. The study accounted for fuel emission during soil restoration but did not account for land use related impacts. In comparison, Clarke et al. [9] also defined their study as a CtFG LCA but excluded the plantation EoL and did consider land use impacts. Though these different methodological applications can be valid, a justification for assumptions is recommended by ISO guidelines since such assumptions directly impact the results. The EoL phase's relevance concerning the study outcome is discussed further in the following section.

Another important finding was regarding data representativity related to foreground and background definitions. According to the results, few studies gave a clear description of the selected foreground or background system. A significance of such distinction is that it helps to discern whether a process is part of the primary or secondary system and defines where primary or secondary data is required. Moreover, it can influence the support to decision making, as these definitions help to communicate which parts of the system can be influenced and modeled. Simultaneously, an ambiguous definition of such systems can lead to confusion rather than guidance [22]. The lack of clarity is reflected by the challenge of identifying whether the data represented the foreground or background system. This implies a further issue when interpreting the results and when a review for transparency or replicability is desired.
Regarding the environmental impact categories evaluated, the results show that more than half of the studies included at least three categories, which are climate change, eutrophication, and acidification. Similar results were given by D'Amato et al. [11] who reported climate change, ozone, eutrophication, human toxicity, resource depletion, acidification, and environmental toxicity as the most common impact categories in forest-based LCAs. The issue of knowing the number of impact categories necessary to evaluate a product life cycle has been discussed by Steinmann et al. [62]. The authors found that, by assessing six impact categories, as CC, OD, land use, marine and terrestrial ecotoxicity, and combined effects of EP and $\mathrm{AD}$, nearly $92 \%$ of the variance in 976 product rankings from the Ecoinvent database are covered. Based on this knowledge, it can be deduced that SRC LCAs have partially developed a comprehensive assessment in terms of evaluation range at a midpoint level. Nevertheless, an important finding is that several studies avoid the inclusion of relevant impact categories, such as biodiversity and land use [10]. Many articles do not justify such exclusion, though these categories are known for their relevance for agricultural plantations. This exclusion undermines the understanding of such LCA results to represent the potential environmental impacts of SRC value chains, as not all environmental issues resulting from the product system are included [21]. The relevance of including the land use category is discussed in the following section.

There is a lack of clear communication of the impact category selection criteria. Though several studies indicated that their choice was based on predefined sets, such as CML, a thorough justification of the selection, as suggested by the ISO standards [13], was missing in most studies. It can be discussed that, in practice, the selection criterion is an essential step in LCA studies, it provides the connection between the LCIA phase and the study's goal, building justification for the exclusion of irrelevant categories. For instance, for an LCA that intends to support a decision-making process while establishing a SRC value chain, it is essential to know why a relevant impact category (e.g., land use) is not assessed. Such communication implies a higher level of transparency that would enable further analysis and hint at the assessment's limitations.

\section{Critical Methodological Options Affecting SRC LCA's Study Outcome}

More than half of the reviewed papers did not include any land use impact in their analysis (Fig. 2), which leads to burdenshifting between the environmental impact categories. Previous studies, such as Pawelzik et al. [10], who focused on LCA of bio-based materials, highlighted the importance of including land use as this can significantly affect the overall study outcome. The land use aspects of relevance are direct land use, direct land-use change, indirect-land use change, soil 
degradation, biodiversity, and water use. One of the reasons that might prevent LCA practitioners from including any land use aspect is the stage of maturity in a methodology. For instance, accounting methods for carbon stocks within the different carbon pools are among the most debated topics in the literature [21], reflecting the not yet consensus on how to assess the related land use impacts. Issues discussed are, among others, the temporal dimension of carbon storage in products, the accounting and allocation methods, and the carbon cycle method. For the studies that did consider land use, it was noticed that SOC stocks were a critical aspect. Djomo et al. [27] calculated the land SOC stocks using a land surface model. Their conclusions draw attention to the impact that SRC plantations have on SOC stocks compared to previous cropland, forest, or marginal land. Also, SOC stocks can be a determinant factor in the SRC value chains net carbon balance calculations, as they count within the carbon sink calculations. Therefore, their accounting can be a critical factor to understanding the potential climate benefits of SRC LCAs.

One of the clear connections is the dependency of identified environmental hotspots and the inclusion of value chain processes. While certainly not all SRC projects include all possible agricultural processes, the exclusion of hotspots identified in the current study can have an important impact on the overall environmental assessment. Hence, considering that SRC projects might have a variety of plantations that require different agricultural practices, LCA studies could dismiss an important environmental impact by not considering the possibility that, for instance, fertilization might be necessary for a particular field during the lifetime of the project. Thus, LCA studies can deliver more holistic results when including a range of scenarios that evaluate the previously identified hotspots.

Besides the inherent partial estimation of a cradle to gate LCA approach, the exclusion of the EoL can mean missing one of the most critical aspects of SRC value chains, which can potentially lead to burden shifting between life cycle stages. The analysis of the reviewed studies revealed that the different EoL options were mainly stump excavation [46], herbicide application [12], mulching of roots [38, 52], tree levelling [54], and soil restoring. Though most studies included one of these EoL options, critical aspects related to land use impacts were not often included. The following points are relevant in the literature: (i) if roots are left in the ground, they can be a potential source of SOC depending on the agricultural management given after the EoL [38]; (ii) root removal can be a potential carbon source due to the loss of carbon within the soil; and (iii) possible impacts on biodiversity. In a recent study by Rowe et al. [63], it was concluded that potential changes in SOC stocks at the plantation EoL could substantially impact the net carbon calculations, and excluding such accounting can lead to misguidance based on an incomplete environmental assessment of SRC.

\section{Research Outlook}

The present study's final objective is to derive gaps in the LCA study of SRC and propose a research outlook for improving the understanding of potential environmental impacts associated with wood production in SRC systems. First, in light of SRC LCAs to support developing a sustainable bioeconomy, it is suggested that such assessments improve the communication of the goal, scope, and limitations of study, as well as the intended audience, foreground and background system definition and argumentation for environmental impact categories selected. This will generate a robust interpretation that leads to a more straightforward transformation of the results into policies [25]. Furthermore, SRC LCAs can benefit by taking into account the methodological findings of the present research. Considering the FU definition, SRC LCAs aiming at a CtFG, as the study of land use or comparison of agricultural technologies, can implement an area or volume-based FU. If the focus expands to consider a $\mathrm{CtGa}$ or CtGr approach, an FU based on the product's function is beneficial, for instance, an energy-based FU.

It is encouraged that future assessments go beyond system comparison and a $\mathrm{CtGa}$ or $\mathrm{CtFG}$ approach. In particular, for SRC value chains, the inclusion of the plantation EoL phase is appropriate, as its exclusion weakens the life cycle thinking suggested by the ISO standards [13], bearing the risk of burden-shifting, underestimation, and misleading conclusions. The plantation EoL involves agricultural operations such as uprooting, land remediation, and land reconversion. These operations could result in SOC loss, influencing the overall carbon calculations, potentially implying a reconsideration of some studies' outcomes [26, 38, 63]. Moreover, the gain of biodiversity is hinted as a potential benefit of SRC plantations; however, further research is needed to understand the EoL phase's consequences. More comprehensive LCA results are obtained by including the effects on land use, such as SOC and biodiversity as their findings could lead to reconsider the overall outcome of LCA results. If partial LCAs are taken as the basis for decision-making in light of supporting a sustainable bioeconomy, there is an inherent risk of underestimating the environmental impacts. Thus, future SRC LCAs should include impacts related to the plantation EoL, fuel consumption for the agricultural machinery and land-use impacts.

The variability of methodological options and the results of the different case studies highlight the relevance of including a sensitivity analysis in future LCA studies of SRC value chains. The following relevant points were deduced from the reviewed articles: (i) regarding input data, many studies accounted for secondary data to perform their calculations. SRC LCAs would strengthen their results by performing a sensitivity analysis to reduce uncertainties attached to using data that is not specific to the case study. Such analysis considers a range of data, thus providing a spectrum of the results 
that is more representative of reality. (ii) Concerning agricultural processes, particularly for LCA studies performed during value chain development, it is suggested to develop a scenario analysis where effects of different agricultural operations are tested, especially concerning the previously identified hotspots, such as harvesting, transportation, fertilization, pesticides, and irrigation. Based on this knowledge, it should be possible to identify development pathways.

As for the limitations of the present study, it can be mentioned that the search strategy was limited to using only two search engines, Scopus and Science Direct. Also, the articles retrieved are reliant on the applied search string. Therefore, it cannot be guaranteed that all relevant articles were included. Nevertheless, this study contributes to understanding the state of the art of SRC LCA studies by presenting an analysis of previous literature and suggesting improvement paths.

\section{Conclusion}

The underlying assumption to be examined was that SRC LCAs are influenced by the selected methodological options, hence challenging the overall understanding of SRC value chains' potential environmental impacts. The finding that previous studies with similar system definitions assume different methodological options adds to the discussion about how flexible the implementation of the LCA framework should be. Nevertheless, it is deduced that future SRC LCAs need to provide clear and systematic reporting of the application purpose, methodological options, and assumptions. This description will help compensate for LCA's methodological flexibility by providing a strong foundation that allows for comparison and interpretation of results. Data uncertainty and sensitivity analysis should be included, since SRC LCAs deal with large amounts of secondary data, affecting the calculation of important impact categories. For instance, analyzing SRC value chains and not considering the various EoL possibilities and their consequences on land use can result in misleading outcomes that affect further decision-making. Future SRC LCAs can benefit from understanding land use related impacts, as this will help improve the modeling of the different agricultural process consequences.

Author Contribution The study conception and design were established by E. Alejandro Perdomo E, and Franziska Hesser. Planning and implementation of the study was done by E. Alejandro Perdomo Echenique and Daniela Fürtner. Data collection was carried out by E. Alejandro Perdomo E. Data analysis and interpretation were performed by E. Alejandro Perdomo E. and Franziska Hesser. The first draft of the manuscript was written by E. Alejandro Perdomo E. and all authors commented on previous versions of the manuscript. All authors read and approved the final manuscript.
Funding This study received funding from the Bio Based Industries Joint Undertaking under the European Union's Horizon 2020 research and innovation programme under grant agreement number 745874 and the Austria Research Agency (FFG) under the COMET program grant number 865905 . Open access funding provided by University of Natural Resources and Life Sciences Vienna (BOKU).

Data Availability The datasets generated and analyzed during the current study are not publicly available to guarantee the protection of confidential information but are available from the corresponding author on reasonable request.

\section{Declarations}

Ethics Approval Compliance with ethical standards was considered by informing participants about the aims and methods of the respective research project. The participation in the survey was on a voluntary basis and anonymity of the participants is preserved - no inferences can be drawn from the answers to the individuals.

Conflict of Interest The authors declare no competing interests.

Open Access This article is licensed under a Creative Commons Attribution 4.0 International License, which permits use, sharing, adaptation, distribution and reproduction in any medium or format, as long as you give appropriate credit to the original author(s) and the source, provide a link to the Creative Commons licence, and indicate if changes were made. The images or other third party material in this article are included in the article's Creative Commons licence, unless indicated otherwise in a credit line to the material. If material is not included in the article's Creative Commons licence and your intended use is not permitted by statutory regulation or exceeds the permitted use, you will need to obtain permission directly from the copyright holder. To view a copy of this licence, visit http://creativecommons.org/licenses/by/4.0/.

\section{References}

1. Sikkema R, Dallemand JF, Matos CT, van der Velde M, SanMiguel-Ayanz J (2017) How can the ambitious goals for the EU's future bioeconomy be supported by sustainable and efficient wood sourcing practices? Scand J For Res 32:551-558. https://doi.org/10. 1080/02827581.2016.1240228

2. Mantau U (2012) Holzrohstoffbilanz Deutschland - Entwicklungen und Szenarien des Holzaufkommens und der Holzverwendung von 1987 bis 2015. Univ Hambg 65

3. Delphin S, Escobedo FJ, Abd-Elrahman A, Cropper WP (2016) Urbanization as a land use change driver of forest ecosystem services. Land Use Policy 54:188-199. https://doi.org/10.1016/j. landusepol.2016.02.006

4. Purkus A, Hagemann N, Bedtke N, Gawel E (2018) Towards a sustainable innovation system for the German wood-based bioeconomy: implications for policy design. J Clean Prod 172: 3955-3968. https://doi.org/10.1016/j.jclepro.2017.04.146

5. San Miguel G, Corona B, Ruiz D, Landholm D, Laina R, Tolosana E, Sixto H, Cañellas I (2015) Environmental, energy and economic analysis of a biomass supply chain based on a poplar short rotation coppice in Spain. J Clean Prod 94:93-101. https://doi.org/10.1016/ j.jclepro.2015.01.070

6. Griffiths NA, Rau BM, Vaché KB, Starr G, Bitew MM, Aubrey DP, Martin JA, Benton E, Jackson CR (2019) Environmental effects of short-rotation woody crops for bioenergy: what is and isn't 
known. GCB Bioenergy 11:554-572. https://doi.org/10.1111/gcbb. 12536

7. Schweier J, Schnitzler J-P, Becker G (2016) Selected environmental impacts of the technical production of wood chips from poplar short rotation coppice on marginal land. Biomass Bioenergy 85: 235-242. https://doi.org/10.1016/J.BIOMBIOE.2015.12.018

8. González-García S, Moreira MT, Feijoo G (2012) Environmental aspects of eucalyptus based ethanol production and use. Sci Total Environ 438:1-8. https://doi.org/10.1016/j.scitotenv.2012.07.044

9. Clarke R, Sosa A, Murphy F (2019) Spatial and life cycle assessment of bioenergy-driven land-use changes in Ireland. Sci Total Environ 664:262-275. https://doi.org/10.1016/j.scitotenv.2019.01. 397

10. Pawelzik P, Carus M, Hotchkiss J, Narayan R, Selke S, Wellisch M, Weiss M, Wicke B, Patel MK (2013) Critical aspects in the life cycle assessment (LCA) of bio-based materials - reviewing methodologies and deriving recommendations. Resour Conserv Recycl 73:211-228. https://doi.org/10.1016/j.resconrec.2013.02.006

11. D'Amato D, Gaio M, Semenzin E (2020) A review of LCA assessments of forest-based bioeconomy products and processes under an ecosystem services perspective. Sci Total Environ 706:135859. https://doi.org/10.1016/j.scitotenv.2019.135859

12. Rutz, D, Dimitriou I (2015) Sustainable short rotation coppice a handbook. WIP Renew. Energies

13. ISO (2006) Environmental management - life cycle assessment — principles and framework - ISO 14040

14. Djomo SN, El Kasmioui O, Ceulemans R (2011) Energy and greenhouse gas balance of bioenergy production from poplar and willow: a review. GCB Bioenergy 3:181-197. https://doi.org/10.1111/j. 1757-1707.2010.01073.x

15. Hansen A, Meyer-Aurich A, Prochnow A (2013) Greenhouse gas mitigation potential of a second generation energy production system from short rotation poplar in Eastern Germany and its accompanied uncertainties. Biomass Bioenergy 56:104-115. https://doi. org/10.1016/j.biombioe.2013.05.004

16. Jiménez-González C, Kim S, Overcash MR (2000) Methodology for developing gate-to-gate life cycle inventory information. Int $\mathrm{J}$ Life Cycle Assess 5:153-159. https://doi.org/10.1007/BF02978615

17. Hauschild M, Goedkoop M, Guinée J, et al (2011) Recommendations for life cycle impact assessment in the European context - based on existing environmental impact assessment models and factors

18. Hauschild MZ, Huijbregts MAJ (2015) Life cycle impact assessment. Springer Netherlands, Dordrecht

19. Eggleston S, Buendia L, Miwa K et al (2006) 2006 IPCC guidelines for national greenhouse gas inventories. Institute for Global Environmental Strategies Hayama, Japan

20. Jolliet O, Margni M, Charles R, Humbert S, Payet J, Rebitzer G, Rosenbaum R (2003) Presemmg a new Meth6d IMPACT 2002+ : a new life cycle impact assessment methodology. Int J Life Cycle Assess 8:324-330. https://doi.org/10.1007/BF02978505

21. Rosenbaum RK, Hauschild MZ, Boulay A-M, Fantke P, Laurent A, Núñez M, Vieira M (2018) Life cycle impact assessment. In: Life cycle assessment. Springer International Publishing, Cham, pp $167-270$

22. Tillman AM, Baumann H (2004) The hitch hiker's guide to LCA : an orientation in life cycle assessment. Lund, Sweden Studentlitteratur $\mathrm{AB}$

23. Hauschild MZ, Rosenbaum RK, Olsen SI (2018) Life cycle assessment. Springer

24. Livoreil B, Glanville J, Haddaway NR, Bayliss H, Bethel A, de Lachapelle FF, Robalino S, Savilaakso S, Zhou W, Petrokofsky G, Frampton G (2017) Systematic searching for environmental evidence using multiple tools and sources. Environ Evid 6:1-14. https://doi.org/10.1186/s13750-017-0099-6
25. A. C, N. R, R. J, et al (2018) Biomass production, supply, uses and flows in the European Union. First results from an integrated assessment

26. Morais MC, Siqueira-Neto M, Guerra HP, Satiro LS, Soltangheisi A, Cerri CEP, Feigl BJ, Cherubin MR (2020) Trade-offs between sugarcane straw removal and soil organic matter in Brazil. Sustain 12:1-13. https://doi.org/10.3390/su12229363

27. Djomo SN, De Groote T, Gobin A et al (2019) Combining a land surface model with life cycle assessment for identifying the optimal management of short rotation coppice in Belgium. Biomass Bioenergy 121:78-88. https://doi.org/10.1016/j.biombioe.2018. 12.010

28. Krzyżaniak M, Stolarski MJ, Warmiński K (2019) Life cycle assessment of poplar production: environmental impact of different soil enrichment methods. J Clean Prod 206:785-796. https://doi. org/10.1016/j.jclepro.2018.09.180

29. Rajabi Hamedani S, Colantoni A, Gallucci F, Salerno M, Silvestri C, Villarini M (2019) Comparative energy and environmental analysis of agro-pellet production from orchard woody biomass. Biomass Bioenergy 129:105334. https://doi.org/10.1016/j. biombioe.2019.105334

30. Lovarelli D, Fusi A, Pretolani R, Bacenetti J (2018) Delving the environmental impact of roundwood production from poplar plantations. Sci Total Environ 645:646-654. https://doi.org/10.1016/j. scitotenv.2018.06.386

31. Ruiz D, San Miguel G, Corona B, López FR (2018) LCA of a multifunctional bioenergy chain based on pellet production. Fuel 215:601-611. https://doi.org/10.1016/j.fuel.2017.11.050

32. Saez de Bikuña K, Hauschild MZ, Pilegaard K, Ibrom A (2017) Environmental performance of gasified willow from different lands including land-use changes. GCB Bioenergy 9:756-769. https:// doi.org/10.1111/gcbb.12378

33. Dias GM, Ayer NW, Kariyapperuma K, Thevathasan N, Gordon A, Sidders D, Johannesson GH (2017) Life cycle assessment of thermal energy production from short-rotation willow biomass in Southern Ontario, Canada. Appl Energy 204:343-352. https://doi. org/10.1016/j.apenergy.2017.07.051

34. Parajuli R, Knudsen MT, Djomo SN, Corona A, Birkved M, Dalgaard T (2017) Environmental life cycle assessment of producing willow, alfalfa and straw from spring barley as feedstocks for bioenergy or biorefinery systems. Sci Total Environ 586:226-240. https://doi.org/10.1016/j.scitotenv.2017.01.207

35. Schweier J, Molina-Herrera S, Ghirardo A, Grote R, Díaz-Pinés E, Kreuzwieser J, Haas E, Butterbach-Bahl K, Rennenberg H, Schnitzler JP, Becker G (2017) Environmental impacts of bioenergy wood production from poplar short-rotation coppice grown at a marginal agricultural site in Germany. GCB Bioenergy 9:1207-1221. https://doi.org/10.1111/gcbb.12423

36. Bacenetti J, Bergante S, Facciotto G, Fiala M (2016) Woody biofuel production from short rotation coppice in Italy: environmentalimpact assessment of different species and crop management. Biomass Bioenergy 94:209-219. https://doi.org/10.1016/j. biombioe.2016.09.002

37. Krzyżaniak M, Stolarski MJ, Szczukowski S, Tworkowski J (2016) Life cycle assessment of new willow cultivars grown as feedstock for integrated biorefineries. BioEnergy Res 9:224-238. https://doi. org/10.1007/s12155-015-9681-3

38. Whittaker C, Macalpine W, Yates NE, Shield I (2016) Dry matter losses and methane emissions during wood chip storage: the impact on full life cycle greenhouse gas savings of short rotation coppice willow for heat. BioEnergy Res 9:820-835. https://doi.org/10. 1007/s12155-016-9728-0

39. Bacenetti J, Pessina D, Fiala M (2016) Environmental assessment of different harvesting solutions for short rotation coppice plantations. Sci Total Environ 541:210-217. https://doi.org/10.1016/j. scitotenv.2015.09.095 
40. Rugani B, Golkowska K, Vázquez-Rowe I, Koster D, Benetto E, Verdonckt P (2015) Simulation of environmental impact scores within the life cycle of mixed wood chips from alternative short rotation coppice systems in Flanders (Belgium). Appl Energy 156: 449-464. https://doi.org/10.1016/j.apenergy.2015.07.032

41. Caputo J, Balogh SB, Volk TA, Johnson L, Puettmann M, Lippke B, Oneil E (2014) Incorporating uncertainty into a life cycle assessment (LCA) Model of short-rotation willow biomass (Salix spp.) crops. Bioenergy Res 7:48-59. https://doi.org/10.1007/s12155013-9347-y

42. González-García S, Moreira MT, Dias AC, Mola-Yudego B (2014) Cradle-to-gate Life cycle assessment of forest operations in Europe: environmental and energy profiles. J Clean Prod 66:188-198. https://doi.org/10.1016/j.jclepro.2013.11.067

43. Ericsson N, Nordberg Å, Sundberg C, Ahlgren S, Hansson PA (2014) Climate impact and energy efficiency from electricity generation through anaerobic digestion or direct combustion of short rotation coppice willow. Appl Energy 132:86-98. https://doi.org/ 10.1016/j.apenergy.2014.06.049

44. González-García S, Dias AC, Clermidy S, Benoist A, Bellon Maurel V, Gasol CM, Gabarrell X, Arroja L (2014) Comparative environmental and energy profiles of potential bioenergy production chains in Southern Europe. J Clean Prod 76:42-54. https://doi. org/10.1016/j.jclepro.2014.04.022

45. Murphy F, Devlin G, McDonnell K (2014) Energy requirements and environmental impacts associated with the production of short rotation willow (Salix sp.) chip in Ireland. GCB Bioenergy 6:727739. https://doi.org/10.1111/gcbb.12111

46. Gabrielle B, Nguyen The N, Maupu P, Vial E (2013) Life cycle assessment of eucalyptus short rotation coppices for bioenergy production in southern France. GCB Bioenergy 5:30-42. https://doi. org/10.1111/gcbb. 12008

47. González-García S, Iribarren D, Susmozas A, Dufour J, Murphy RJ (2012) Life cycle assessment of two alternative bioenergy systems involving Salix spp. biomass: bioethanol production and power generation. Appl Energy 95:111-122. https://doi.org/10.1016/j. apenergy.2012.02.022

48. González-García S, Mola-Yudego B, Dimitriou I, Aronsson P, Murphy R (2012) Environmental assessment of energy production based on long term commercial willow plantations in Sweden. Sci Total Environ 421-422:210-219. https://doi.org/10.1016/j. scitotenv.2012.01.041

49. González-García S, Bacenetti J, Murphy RJ, Fiala M (2012) Present and future environmental impact of poplar cultivation in the Po Valley (Italy) under different crop management systems. J Clean Prod 26:56-66. https://doi.org/10.1016/J.JCLEPRO.2011.12.020

50. Kunstmann M (2012) Comperative LCA of wood from conventional forestry and wood from short rotation coppice. Tech Univ Dresden

51. Brandão M, Milà i Canals L, Clift R (2011) Soil organic carbon changes in the cultivation of energy crops: implications for GHG balances and soil quality for use in LCA. Biomass Bioenergy 35: 2323-2336. https://doi.org/10.1016/j.biombioe.2009.10.019

52. Gilbert P, Thornley P, Riche AB (2011) The influence of organic and inorganic fertiliser application rates on UK biomass crop sustainability. Biomass Bioenergy 35:1170-1181. https://doi.org/10. 1016/j.biombioe.2010.12.002
53. Butnar I, Rodrigo J, Gasol CM, Castells F (2010) Life-cycle assessment of electricity from biomass: case studies of two biocrops in Spain. Biomass Bioenergy 34:1780-1788. https://doi.org/10.1016/ j.biombioe.2010.07.013

54. Fantozzi F, Buratti C (2010) Life cycle assessment of biomass chains: wood pellet from short rotation coppice using data measured on a real plant. Biomass Bioenergy 34:1796-1804. https:// doi.org/10.1016/j.biombioe.2010.07.011

55. Roedl A (2010) Production and energetic utilization of wood from short rotation coppice-a life cycle assessment. Int J Life Cycle Assess 15:567-578. https://doi.org/10.1007/s11367-010-0195-0

56. Gasol CM, Gabarrell X, Anton A, Rigola M, Carrasco J, Ciria P, Rieradevall J (2009) LCA of poplar bioenergy system compared with Brassica carinata energy crop and natural gas in regional scenario. Biomass Bioenergy 33:119-129. https://doi.org/10.1016/j. biombioe.2008.04.020

57. Goglio P, Owende PMO (2009) A screening LCA of short rotation coppice willow (Salix sp.) feedstock production system for smallscale electricity generation. Biosyst Eng 103:389-394. https://doi. org/10.1016/j.biosystemseng.2009.03.003

58. Keoleian GA, Volk TA (2005) Renewable energy from willow biomass crops: life cycle energy, environmental and economic performance. CRC Crit Rev Plant Sci 24:385-406. https://doi.org/10. 1080/07352680500316334

59. Heller MC, Keoleian GA, Volk TA (2003) Life cycle assessment of a willow bioenergy cropping system. Biomass Bioenergy 25:147165. https://doi.org/10.1016/S0961-9534(02)00190-3

60. Lettens S, Muys B, Ceulemans R et al (2003) Energy budget and greenhouse gas balance evaluation of sustainable coppice systems for electricity production. Biomass Bioenergy 24:179-197. https:// doi.org/10.1016/S0961-9534(02)00104-6

61. Moreno Ruiz E, Valsasina L, Brunner F et al (2018) Documentation of changes implemented in ecoinvent database v3.5. Ecoinvent, Zürich. Switzerland. 5:1-97

62. Steinmann ZJN, Schipper AM, Hauck M, Huijbregts MAJ (2016) how many environmental impact indicators are needed in the evaluation of product life cycles? https://doi.org/10.1021/acs.est. $5 \mathrm{~b} 05179$

63. Rowe RL, Keith AM, Elias DMO, McNamara NP (2020) Soil carbon stock impacts following reversion of Miscanthus $x$ giganteus and short rotation coppice willow commercial plantations into arable cropping. GCB Bioenergy 12:680-693. https://doi.org/ $10.1111 /$ gcbb. 12718

64. Goedkoop MJ, Heijungs R, Huijbregts M, et al (2013) ReCiPe 2008, A life cycle impact assessment method which comprises harmonised category indicators at the midpoint and the endpoint level; first edition report I: characterisation; 6 January 2009. 133. http://www.lcia-recipe.net

65. Environdec (2013) Characterization factors for default impact assessment categories. In: EPD Int. AB, Stock. Sweden. https://www. environdec.com/Creating-EPDs/Steps-to-create-an-EPD/PerformLCA-study/Characterisation-factors-for-default-impactassessment-categories. Accessed 3 Mar 2020

Publisher's Note Springer Nature remains neutral with regard to jurisdictional claims in published maps and institutional affiliations. 